\title{
A PESTE NO BRASIL: A INTRODUÇÃO DAS IDEIAS FREUDIANAS NO BRASIL A PARTIR DA MEDICINA E DO MODERNISMO
}

Luciana Torquato e Guilherme Massara Rocha

Luciana Torquato

Guilherme Massara Rocha

Universidade Federal de Minas Gerais (UFMG), Departamento de Psicologia, Belo Horizonte/MG, Brasil.
RESUMO: Apresenta-se o momento histórico da entrada da teoria freudiana no Brasil como um processo que esteve intimamente relacionado às demandas da intelligentsia nacional em seu esforço de construção do projeto de nação que ecoava no país desde o final do séculoXIX.Ao identificarmos as duas vias discursivas de apropriação da psicanálise no Brasil, a medicina higienista e a arte modernista brasileira, pretendemos, neste estudo, indicar os traços que esses pontos de ancoragem deixaram no processo de construção do movimento psicanalítico nacional.

Palavras-chave: Higienismo, história, modernismo, psicanálise.

ABSTRACT: The pest in Brazil: the introduction of Freudian ideas in Brazil from medicine and modernism. This article presents the historical period of the introduction of Freudian theory in Brazil as a process that was closely related to the national intelligentsia's interests and their efforts to enhance a great cultural project that was already being conceived from the late nineteenth century. By identifying the two distinct ways of appropriation of psychoanalysis in Brazil, medicine hygienist and Brazilian modernist art, this article alsoindicatestheimpactand consequences of thesetwomovements on the beginning of the psychoanalytical movement in Brazil. Keywords: Hygienist, history, modernism, psychoanalysis.

DOI - http://dx.doi.org/10.1590/S1516-14982016003005 


\section{A PESTE}

Em 1909, Sigmund Freud desembarca na América do Nortena companhia de seus colegas médicos Ferenczi, Jung, Yung, Brill e Ernest Jones. Convidado por Stuart Hall, Freud se dirige aos Estados Unidos para proferir palestras introdutórias sobre a psicanálise. Tal viagem possibilitou a expansão da teoria freudiana no novo mundo, estendendo seus domínios para além do continente europeu. Tratava-se de um deslocamento traçado com o intuito de atender à aspiração freudiana de garantir a ampliação de sua disciplina, fugindo da censura, das críticas e, por vezes, da indiferença, antissemitismo e germanofabia presentes em alguns dos países daquele continente.

Conta-nos Roudinesco que, em 1955, numa conferência proferida em Viena, o psicanalista francês Jacques Lacan confessou ter escutado de Carl Gustav Jung o relato de que na ocasião da viagem do grupo de psicanalistas à América do Norte, Freud teria segredado no ouvido de seu discípulo, ao avistar a Estátua da Liberdade no porto novaiorquino, a seguinte sentença: "Eles não sabem que lhes estamos trazendo a peste" (ROUDINESCO \& PLON, 1997, p.587).

A peste freudiana contaminou o novo mundo, ultrapassou barreiras geográficas, logo se disseminando pela terra brasilis. As referências clássicas que tratam da introdução da psicanálise no país em sua maioria revelam ter sido o pensamento freudiano trazido e disseminado pelos médicos e psiquiatras, prioritariamente, nas cidades de São Paulo e Rio de Janeiro. Registros mais remotos relatam que Juliano Moreira, médico fundador da psiquiatria moderna no Brasil, teria aplicado as ideias freudianas durante suas aulas na Faculdade de Medicina na Bahia ainda no ano de 1899. Julio Pires Porto-Carrero, psiquiatra, psicanalista, primeiro historiador da teoria freudiana no país, também dedicou-se vigorosamente ao estudo de Freud, criando, em 1926, no Rio de Janeiro, a Clínica de Psicanálise da Liga Brasileira de Higiene Mental (OLIVEIRA, 2002).

Textos históricos ${ }^{1}$ nos revelam que, em São Paulo, o debate acerca das ideias freudianas se iniciou na década de 1920 a partir da publicação do livro $A$ doutrina pansexualista de Freud, do médico Franco da Rocha, principal expoente da psiquiatria local, idealizador e fundador do Hospital Psiquiátrico do Juqueri. Ainda na capital paulista, em 1927, Durval Marcondes e Franco da Rocha organizaram a primeira sociedade psicanalítica da América Latina, a Sociedade Brasileira de Psicanálise (SBP).

No entanto, não é da via psiquiátrica a primazia na expansão da psicanálise na capital paulista: foi também graças à grande difusão no meio intelectual e, sobretudo, literário, que as ideias freudianas ganharam corpo no país. Ao visi-

\footnotetext{
${ }^{1}$ Referências históricas interessantes podem ser encontradas nos textos das psicanalistas Virginia Bicudo (1948) e Marialzira Perestrello (1987). As duas autoras são nomes importantes na construção da historiografia da psicanálise no Brasil.
} 
tarmos as produções literárias produzidas durante o período em questão, percebemos que o pensamento psicanalítico já circulava entre os salões intelectuais brasileiros desde a década de 1910. Além dos psiquiatras que se informavam das teorias freudianas pormeio de artigos de revistas especializadas, alguns viajantes - como o próprio Oswald de Andrade, por exemplo — frequentaram a Paris moderna, trazendo consigo as propostas freudianas, ainda que a partir de uma leitura "contaminada" pelas vanguardas europeias.

Pretende-se demonstrar como as décadas iniciais do século XX marcaram um período privilegiado de incorporação das ideias freudianas no país, sobretudo através de duas vias distintas: a medicina psiquiátrico-higienista, com sua leitura reformista e universalizante da psicanálise, e a arte modernista, com a leitura contestatória dos códigos sociais e morais dominantes.

\section{A PSICANÁLISE NA CONSTRUÇÃO DE UMA NAÇÃO MODERNA: A APROPRIAÇÃO MÉDICO-HIGIENISTA}

A virada do século XIX para o século XX marcou as duas grandes transformações da sociedade brasileira. A abolição da escravidão e a implantação da República introduziram o país e sua inteligência num movimento de reformulação das ideias e concepções a respeito do Brasil e de seu povo.

Se a inscrição formal na ordem republicana não foi capaz de alterar de modo radical o estado geral da nação (PATTO, 1999), a abolição da escravatura representavauma questãomaisagudaepreocupantepoisescancaravaadificuldadede integrar no país um excesso populacional que representava um empecilho concreto para seu desenvolvimento. Assim, a questão doaprimoramento racial surgecomo solução perante um diagnóstico que atribuía à raça a existência das mazelas que afligiam esta população desamparada. No entanto, a inteligência nacional não era uníssona ao tratar a questão, assumindo desde posições autoritárias - que apontavam, por exemplo, para a necessidade de constituição de uma nova raça através da crescente incorporação de contingentes brancos — até aquelas que propunham maior intervenção estatal para fornecer à população padrões mais satisfatórios de saneamento e educação (PONTE, 1999).

O Brasil de então enfrentava uma série de entraves advindos do processo de modernização: o desenvolvimento desordenado das cidades, o crescimento populacional e a ausência de infraestrutura primária agravaram de maneira significativa as condições sanitárias observadas nos centros urbanos do país (SEVCENKO, 1992). Se faziam cada vez mais urgentes a organização do processo de urbanização das cidades, a promoção da saúde da população, a formulação de soluções para esses problemas advindos com a urbanização e o crescimento. 
A ciência médica se lança na tentativa de regulação e organização do funcionamento social na perspectiva sanitária. Passa a tratar não só do corpo doente do sujeito, mas do corpo social, supervisionando a saúde da população com o intuito primordial degarantir a segurança e prosperidadeda nação. Nesse sentido, a comunidade médica e científica empenhava-se na construção de um projeto civilizatório-educativo na Primeira República. Tratava-se de educar a população a partir de uma concepção mais ampla de pedagogia moral e cívica: educar o povo indisciplinado, inculto, de maus hábitos. Para a medicina de então, fortemente influenciada pela teoria da degenerescência, a miscigenação do povo era tomada como um entrave crucial para a realização do projeto de civilização da nação (ROCHA, 1983). Nosso primitivismo, marcado pela herança africana e indígena, era tomado como o excesso de paixões, instintivo, contrário ao controle esperado para a afirmação de um estado nacional moderno e civilizado. A psiquiatria se apresenta como um saber que poderia auxiliar sobremaneira esse projeto educativo e civilizatório do povo brasileiro.

O discurso psicanalítico pouco a pouco se inscrevia nesse movimento eugênico que se alastrou pelo país. As ideias freudianas passam a servir como possibilidade de tratamento para a classe débil e impotente do povo brasileiro, que precisaria ser "reformado" para se modernizar e evoluir (PORTO-CARRERO, 1933).

A disciplina freudiana configurar-se-ia como uma panaceia, uma teoria capaz deabarcaros problemas decorrentes doadvento da modernidade,"constituindose em um poderoso instrumento de investigação e explicação do homem e de suas relações em sociedade" (PONTE, 1999, p.27).

Juliano Moreira tornou-se o diretor do Hospital Nacional dos Alienados, no Rio de Janeiro, congregando nesta instituição vários discípulos que, com ele, se empenharam no estudo das ideias freudianas (SAGAWA, 1994). Um desses médicos é o psiquiatra Julio Pires Porto-Carrero, "fanático da psicanálise", cuja trajetória nos ajuda a compreender a apropriação higienista que foi feita do discurso psicanalítico no período.

Ao mesmo tempo em que prescrevia a aplicação da teoria freudiana aos mais variados espectros da vida cotidiana - "na vida diária, pedagogia, até mesmo comércio, (...) inquéritos judiciários, sistemas penitenciários" (PORTO-CARRERO, 1929, p.159), Porto-Carrero defendia vigorosamente a eugenia e higiene mental como bandeiras a serem travadas em prol de uma regeneração da raça e do povo brasileiro. De tal forma que o psiquiatra empenha um movimento para conferir à psicanálise um valor enquanto método de investigação, instrumento

\footnotetext{
2 Em 1925, durante uma comunicação à Sociedade Brasileira de Neurologia, Psiquiatria e Medicina Legal, Porto-Carrero afirmou ser um "convicto" da ciência de Freud. Anos depois, em 1928, definiu-se como "um fanático da psicanálise" (SAGAWA, 2004).
} 
nosográfico que poderia auxiliar na restauração, estabelecimento e manutenção da ordem moral e social. As palavras de Franco da Rocha são esclarecedoras:

\begin{abstract}
"Há na psicanálise um ponto de vista pedagógico de grande alcance. Ela considera como questão capital no determinismo psíquico do indivíduo o desenvolvimento regular e harmônico dos componentes do instinto sexual infantil. É no nosso defeituoso e nocivo hábito de ignorar as exigências da libido, de ocultá-las por completo, que se deve procurar a causa das moléstias e da degeneração da espécie. A psicanálise tem, por isso, um valor iniludível para a ciência eugênica, que hoje ocupa a atenção da classe médica." (ROCHA, 1930, p.69)
\end{abstract}

A psicanálise vai sendo pensada pelos adeptos da eugenia como uma terapêutica que poderia corrigir os vícios, taras e desvios através da associação livre de ideias, da análise onírica, das parapraxias, bem como pela análise direta das crianças.

A matriz discursiva da psicanálise no Brasil ganha destaque em sua leitura do campo social. A psicanálise vai sendo deslocada de sua face singular, de clínica e terapêutica para o campo mais amplo da psicologia coletiva, o que levou a possibilidades inusitadas de leitura da identidade nacional em formação (PONTE, 1999). Nossos médicos, psiquiatras, educadores, higienistas utilizam-se do discurso psicanalítico, do tema da sexualidade, em especial, tanto num viés moralizante, quanto para construção da identidade do homem brasileiro. Educar e prevenir indicavam a possibilidade de regenerar o brasileiro, considerado improdutivo, indisciplinado, doente (RUSSO, 1997). A temática da sexualidade, empreendida por Freud, reverbera na reflexão dos intelectuais brasileiros em sua vontade de contribuir para o debate sobre a identidade nacional. Vale lembrar ainda a importância atribuída à problemática sexual nas campanhas higienistas e pedagógicas características do período, que apontam para um modelo moralizador de disciplina e controle das normas e práticas sociais.

"Acho que, como primeira etapa na solução do problema da educação sexual, seria útil interessar nos estudos psychanalyticos a nossa classe professoral. Foi o que procurei fazer com o curso que ha pouco tive occasião de realizar na Sociedade de Educação. Uma vez senhores das linhas geraes da psychologia freudiana, esses elementos poderiam seleccionar suas leituras, orientando-as para as obras de psychanalyse infantil e pedagógica, que hoje são innumeras. Tal aprendizado theorico seria - é claro - completado com o estudo directo da criança sob o ponto de vista psychanalytico. Só com esse trabalho preliminar de especialização é que se poderiam formar technicos que orientassem entre nós a organização da educação 
sexual, missão delicada na qual serão sempre poucos o saber e a prudência." (MARCONDES apud OLIVEIRA, 2002, p.145)

Orelato do psiquiatra Durval Marcondes, considerado o primeiro psicanalista brasileiro, deixa entrever como o discurso médico psiquiátrico tomava a sexualidadedo povoe, concomitantemente, propunhaas soluções para seus problemas: ao mesmo tempo em que se debruçam sobre a psicanálise no entendimento de suas questões, é evidente que nessa leitura, Durval e seus pares mesclam disciplina freudiana e formulações higienistas, atribuindo à psicanálise um estatuto pedagógico e moralizante radicalmente diferente daquele indicado por Freud.

Énesse ponto de amálgama que une psicanálise evia eugênica que a sexualidade seapresenta aos médicos da época como ponto nevrálgico de intervenção: no plano biológico era preciso pensar em formas de cruzamentos adequados para melhorar a raça; no plano moral, seria preciso educar o povo quanto aos hábitos e comportamentos condizentes aos de uma vida sadia.

As palavras de Porto-Carrero são elucidativas:

"[...] o interesse da espécie está acima do interesse da sociedade contemporânea e muito acima do indivíduo que nada maisé do quea célula periodicamente renovável do grande organismo da espécie. Urgiria, pois que o Estado-providência assumisse o encargo de prover o bom resultado de uniões reprodutoras na espécie humana, tal como o faz a respeito dos animais de corte. Para esse fim, o meio que mais rapidamente ocorre é o do exame médico pré-nupcial, como forma a assegurar a perfeita validez da progênie (PORTOCARRERO, 1929, p.77, grifos nossos)

Eafirma seu ponto de vista de uma pedagogia sexual a partir das bases freudianas: "Dada a profunda influência da sexualidade na formação e operação da psyche infantil, não é justo que a educação se furte ao lado sexual da vida e repila, simplesmente, como immoraes, as manifestações e os conhecimentos sexuais. Urge fazer a educação sexual" (PORTO-CARRERO, 1927, p.58-59, grifos nossos).

Assimsendo, parece-nos patenteaincorporaçãodas contribuições deFreudao discurso eugênico. A reelaboração a que é submetida a psicanálise nos permite, além disso, divisar a tentativa desses psiquiatras de sanear povo e sociedade doentes, expurgando, no entanto, qualquer derivação freudiana que não se coadunasse com sua coletânea de preceitos e receitas higienistas e moralistas.

Nesse mesmo Brasil acometido pelos entraves da urbanização e de ações higienistas e eugênicas, surgem as figuras inquietantes e provocadoras do movimento modernista brasileiro que, a seu próprio modo, deglutiram as ideias freudianas, antropofagicamente transformando, renovando e se servindo da psicanálise para a construção de seus empreendimentos artístico-estéticos. 


\section{A PSICANÁLISE NA CONSTRUÇÃO DE UMA NAÇÃO MODERNISTA:}

\section{A APROPRIAÇÃO DA VANGUARDA ARTÍSTICA}

Discorrendo sobre a história da psicanálise na França, Elizabeth Roudinesco (1994) relata a associação da disciplina freudiana à estética vanguardista, que teria se dado desde os anos iniciais do século XX naquele país. Na circunstância francesa, foi pública e notória a aproximação das ideias freudianas aos experimentos estéticos empreendidos pelos surrealistas. O pensamento freudiano e o descentramento dele proveniente permitiram romper as amarras nas artes, uma vez que trouxeram novidades fundamentais à linguagem. Freud, ao considerar prioritariamente aquilo que até então não tinha sido valorizado - o inconsciente - transformou de modo radical a apreensão do fazer artístico, da obra e do criador (PERESTRELLO, 1994).

No entanto, sabemos de antemão da reticência freudiana com relação aos modernistas e à arte moderna. Freud, apesar de utilizar obras artísticas em seus textos, chegou a dizer em algumas correspondências que os modernistas não poderiam ser chamados de artistas, uma vez que a arte moderna não merecia a designação de arte (KON, 1996).

A psicanálise, no entanto, acabou se tornando tributária dos movimentos vanguardistas no que diz respeito à sua difusão em algumas sociedades - o caso brasileiro, como veremos, retrata tal asseveração. Esses movimentos, em nome do rompimento com todos os padrões vigentes e da busca por uma expressão revolucionária que irromperia do inconsciente, se aproximaram das teorias freudianas, possibilitando a divulgação das mesmas.

Os movimentos de vanguarda buscavam, cada um a seu modo, a valorização do "irracional", do espontâneo e de uma expressão mais livre para a composição. Essa busca é contemporânea à descoberta do inconsciente freudiano e não é de se espantar que este conceito se torne a fonte temática para a criação artística da época. No entanto, o apelo exagerado utilizado por esses artistas em seus procedimentos plásticos deformava o que Freud postulou sobre a instância do inconsciente. Para ele, o inconsciente não era esse irracional, mas um sistema dotado de leis - de uma racionalidade, portanto - próprias.

No Brasil, a intelectualidade artística que nascia no bojo da modernidade apreendia da obra freudiana, ainda precocemente, a possibilidade de atualização deseusideais estéticos, fonte de renovaçãoestilística queia desdea possibilidade inusitada de construção de um vocabulário ampliado - é recorrente o uso de termos como pulsão, libido, inconsciente, subconsciente nessas obras —, até a possibilidade de oferecer à intelectualidade modernista uma maneira outra de construção de seus personagens, dos conflitos psicológicos e do processo de criação literária (PERESTRELLO, 1994). 
Essa outra via de incorporação das ideias freudianas no Brasil não se encontra, entretanto, desvinculada da apropriação médico-psiquiátrica cotejada no primeiro momento deste trabalho. Ora, se os nomes de nossa psiquiatria se valeram das proposições freudianas para a construção de um entendimento do povo brasileiro - e de sua educação moral, sexual, civilizatória -, a classe artística contemporâneaaessesnomestratoutambém deempreendersuaanálise do Brasil e de seu povo, recorrendo, outrossim, aos textos freudianos em seu projeto intelectual.

Além da apropriação feita pelos nomes da psiquiatria local, a psicanálise começa a impactar, ainda que de modo tímido, a produção literária de alguns nomes do modernismo. A partir da leitura de alguns desses textos, percebemos como a história da difusão da teoria freudiana no Brasil se encontra radicalmente associada aos primeiros anos da vanguarda artística no país.

Ocenário para nosso enredo permanece o mesmo: tratava-se de um país que recentemente superoua economia escravista ea condição de colônia portuguesa e que, ainda assim, entendia seu contingente de ex-escravos, negros, índios, loucos, pobres e doentes como um entrave crucial para seu desenvolvimento como nação. A solução forjada pela intelectualidade da época passava pelo aprimoramento da raça e das condições de vida do povo.

Um novo espírito de época vai se alinhavando, produzindo um discurso atravessado pela perda das certezas, questionamento dos valores, do saber sobre si próprio, produzindo, como nos conta Facchinetti (2003a), sujeitos em crise de identidade, sem referências. É esse sujeito que entoará o nome da psicanálise na sociedade urbana brasileira nas décadas iniciais do século XX. "Os nossos modernistas se informaram pois rapidamente da arte europeia de vanguarda, aprenderam a psicanálise e plasmaram um tipo ao mesmo tempo local e universal de expressão, reencontrando a influência europeia por um mergulho no detalhe brasileiro." (CANDIDO, 2000, p.128-129).

Ao se referir à dialética entre o cosmopolitismo (universal) e localismo (da ordem do singular), Candido nos lembra que uma das importâncias do movimento foi essa sua capacidade de renovação do pêndulo entre os dois opostos, produzindo uma síntese entre os desígnios europeus e a busca pela identidade nacional. O objeto de interpretação da inteligência nacional não se situava mais exclusivamente na figura europeia, mas também no índio, no negro e em suas misturas. É nesse "caldo cultural" que a obra freudiana é introduzida no país, como um discurso que apontava para a precariedade do estatuto da consciência e da verdade, permitindo aos intelectuais considerar novas formas de civilidade 
e socialização, para além da forma de civilização única e homogênea que vinha sendo imaginada até então. ${ }^{3}$

Esse grupo de jovens artistas e intelectuais em formação no país exprimia um enorme desejo de renovação cultural, política e social, fortemente engajado na busca da identidade nacional. Martins (1987) nos revela que essa procura passava sobretudo pela contestação dos cânones estéticos consagrados na vida cultural, estendendo-se, ainda assim, para as áreas diversas como a biologia, física, química, enfim, às experimentações científicas das mais variadas ordens. A psicanálise, pelo que podemos apreender, teria se configurado como mais um saber disponível a esse experimentalismo.

Todaarenovaçãoestéticaempreendidaporessesartistas, abuscadasfiguras do povo, do popular, do coloquial, a nossa matriz africana, essa reconfiguração dos temas da arte foram acompanhadas pela renovação da forma artística: o humor, o sarcasmo, a ironia e o discurso jocoso, elementos esses tipicamente nacionais são empenhados pela intelligentsia nacional em sua tentativa de "descobrimento" do Brasil e de seu povo.

Animados pelo espírito moderno que circundava o mundo ocidental, tais artistas, de forma libertária e destrutivo-construtiva, ${ }^{4}$ teciam um amplo movimento cultural-estético-ideológico de forte repercussão no cenário das artes e na sociedade brasileira no início do século XX. A nova perspectiva aberta por esses nomes da inteligência nacional acabou alavancando uma série de questionamentos a respeito da consciência e da unificação nacional. A partir desse movimento passarão, com o auxílio dos ensinamentos freudianos, a "denunciar todos os recalques da nação" (FACCHINETTI, 2001). A história do país começa a ser considerada a partir de sua possibilidade de revisitar o passado num exercício contínuo de ampliação do debate em torno das tradições culturais, a fim de perceberas discussões que serviram comofonte para as interpretações sobrea nação.

Diante da incerteza sobre o que seria o nosso povo, sua constituição étnica mestiça, um povo que não seria solidamente formado, ${ }^{5}$ os modernistas passam, a partir da influência da psicanálise, a repudiar o positivismo, o mundo natural dado de antemão, o darwinismo - figuras da iconografia romântica.

\footnotetext{
${ }^{3}$ Facchinetti e Ponte (2003) citam ainda os nomes de Friedrich Nietzsche e Karl Marx como os outros dois teóricos que, com Freud, formavam a tríade de intelectuais que influenciaram fortemente o pensamento político, social e cultural dos modernistas brasileiros.

${ }^{4}$ Interessante acompanhar as visões de Silviano Santiago e Mario de Andrade sobre o caráter criador ou não do movimento modernista. Para conferir maiores detalhes sobre esse debate, é bastante enriquecedora a leitura do artigo de Santiago (2009).

5 "O Brasil é a realização derradeira e penosa dessas gentes tupis, chegadas à costa atlântica umou dois séculos antes dos portugueses, eque, desfeitas etransfiguradas, vieram darno que somos (...) A assunção de sua própria identidade pelos brasileiros, como de resto por qualquer outro povo, é um processo diversificado, longo, dramático" (RIBEIRO, 1995, p.130-131).
} 
Os conceitos freudianos como inconsciente, pulsão, divisão subjetiva passam a compor um novo discurso e os modernistas se valerão do mesmo em sua análise ética e estética do mundo.

Percorrendotrechos davastaobradomultifacetadoescritorMáriodeAndrade, podemos entrever como teria se dado a influência do discurso psicanalítico na revolução cultural, ideológica eartística proposta pornossos artistas modernistas. Mário de Andrade, legítimo representante do movimento modernista brasileiro, um dos fundadores e figura central do movimento, nos legou um material primoroso para o estudo e interpretação do Brasil. A partir de sua obra, podemos ver como o autor de Macunaíma organizou, de forma cuidadosa, toda sua obra. Esse rico material, disponível para pesquisa no Instituto de Estudos Brasileiros ${ }^{6}$ — na USP —, nos auxilia a compreender como Mário de Andrade e seus pares se serviram das ideias freudianas em suas formulações sobre o movimento vanguardista que propunham, bem como para arremate de suas obras e formulação da noção de um país e de seu povo.

Nossos modernistas se empenharam de maneira efetiva no estudo do Brasil. O crítico literário Silviano Santiago (2009) eleva esses artistas à categoria de grandes intérpretes do país, nossos pioneiros nas ciências sociais. Utilizando, cada um a seu modo, um método particular de estudo e investigação, os modernistas brasileiros teriam vasculhado a língua do povo, a cultura, o regional, o coloquial, a música, o folclore, os costumes, o modo de ser brasileiro.

"Manifestando-seespecialmente pela arteo movimento modernistafoio prenunciador, o preparador e por muitas partes o criador de um estado de espírito nacional. A transformação social do mundo com a quebra gradativa dos grandes impérios, a prática europeia de novas ideologias políticas, a rapidez dos transportes e mil e uma outras causas internacionais, bem como o desenvolvimento da consciência americana e nacional, os progressos internos da técnica e da educação impunham a criação de um espírito novo e exigiam a reverificação e mesmo a remodelação da inteligência brasileira. Isto foi o movimento modernista, de que a Semana de Arte Moderna ficou sendo o brado coletivo principal." (ANDRADE, 1978, p.231)

A partir de contato mais dedicado com a obra de Mário de Andrade notamos que o interesse do escritor, e de alguns de seus contemporâneos, não se situa, de forma geral, na beleza histérica ou na estilística onírica, como foi feito pelos vanguardistas franceses. $O$ material sequestrado ${ }^{7}$ da história do Brasil e de seu

\footnotetext{
${ }^{6}$ O Instituto de Estudos Brasileiros (IEB) foi criado pelo historiador Sergio Buarque de Holanda em 1962, sendo um órgão de integração da Universidade de São Paulo.

${ }^{7}$ Otermo sequestroéuma tradução feita pelo poeta eescritor Mário de Andrade para o termo francês refoulement que, por sua vez, éa tradução do termo original freudiano Verdrängung.
} 
povo, isso que teria sido deslocado, recalcado de nosso discurso e história, passa a ser objeto passível de leitura. A psicanálise é elevada ao campo social, lida e deglutida por nossos artistas modernistas que visavam à construção da noção de identidade nacional.

Nossos modernistas valeram-se prioritariamente das noções e conceitos freudianosque pudessemajudá-los na compreensão do queseriamos sequestros brasileiros: o canibalismo, o recalque, o primitivo, o inconsciente. Cada um desses temas percorridos deixa entrever alguns dos vários elementos que teriam sido apagados, retirados da história da nação, sendo, no entanto, tão necessários à constituição identitária do povo brasileiro.

Diferentemente dos surrealistas franceses, que em sua predileção pela figura da histérica e pela fileira mais plástica e estética, por assim dizer, da psicanálise freudiana, os modernistas brasileiros recorreram a Freud para ilustrar as características psíquicas de seus personagens, escancarar a decadência da sociedade patriarcal, valorizando desmesuradamente uma espécie de ode ao matriarcado. A valorização do primitivo aparece de forma recorrente na obra de uma geração de modernistas, exemplificando certa ida ao texto freudiano para construção de algo que pudesse abarcar a constituição da cultura nacional. Esses artistas tomavam a história do povo como sendo ancorada em um ponto mais profundo e inconsciente de nossa sociedade (MAGGIE, 2005). Forjava-se uma analogia entre a infância do sujeito e a pré-história do Brasil como pontos fundamentais na genealogia dos mesmos. Essas fases, por sua vez, seriam como fontes primordiais de conhecimento de suas histórias, e precisariam ser acessadas e descobertas para que constituíssem um sujeito e um brasileiro dono de si próprio e de sua trama (FACCHINETTI, 2003a).

Macunaíma éa obra clássica que nos serve como paradigma para compreender a aliança travada por Mário de Andrade entre o freudismo e a proposição do primitivismo. Macunaíma constitui o sintoma da cultura nacional, a expressão do psiquismo brasileiro. Sobre o clássico, o próprio Mário nos conta:

"Oquemeinteressou por Macunaímafoi incontestavelmentea preocupaçãoem que vivo de trabalhar e descobrir o mais que possa a entidade nacional dos brasileiros. Ora depois de pelejar muito verifiquei uma coisa que me parece certa: o brasileiro não tem caráter. (...). E com a palavra caráter não determino apenas uma realidade moral não, em vez, entendo a entidade psíquica permanente, se manifestando por tudo, nos costumes, na ação exterior, no sentimento, na língua, na História, na andadura,

Encontramosnaobra deMáriomomentosemquea palavra sequestroaparececomosinônimo de recalque, no sentido psicanalítico do termo. No entanto, em outros momentos, o termo é usado em sentido mais amplo para indicar algum mecanismo inconsciente, ou seja, um deslocamento, uma condensação, a sublimação, dentre outros (LOPEZ, 1996). 
tanto no bem como no mal (...). Macunaíma é um herói surpreendentemente sem caráter." (ANDRADE, 2001, p.169, grifos nossos)

Dessa forma, numa tentativa de esquematizar a entidade psíquica do brasileiro, Mário de Andrade imortaliza esse personagem indigente, que, arranjando-se com aquilo que vai encontrando pelo caminho, é definido então como o sem caráter. Macunaíma é o ponto alto do pensamento de Mário em sua tentativa de pensar o povo brasileiro em toda sua pluralidade e indeterminação.

Vanessa Riaviz (2004) nos faz lembrar que foi justamente ao estudar ofolclore e a tecer toda essa construção que desemboca em Macunaíma, que Mário acaba criando o termo sequestro a partir do recalque freudiano numa tentativa, segundo a autora, de abrigar os termos recalcamento e sublimação, criando essa tradução própria que acaba recobrindo a extensão de tais conceitos.

O contato com a teoria freudiana teria orientado Mário de Andrade e seus pares a tecer uma série de críticas com relação às mazelas modernas que acometiam o país. A partir da leitura de textos ${ }^{8}$ freudianos, esses artistas passam a entender a memória brasileira e a construção sobre a nacionalidade como efeitos de um recalque primordial, que teria excluído, sequestrado o primitivo, o homem brasileiro como símbolo de afeto, sexualidade, desejo.

A partir ainda da leitura freudiana, o campo cultural passa a ser pensado a partir da positivação do que havia sido subjugado durante séculos. E é assim que pensamos a expressão de Antonio Candido (2000) quando este evoca o desrecalque localista: aquilo que até então fora denominado como valor de menos, incompetente, seja por questões raciais, por estar fora dos centros ou pela pobreza, aquilo que até então era periferia, arcaico, popular, ganha um sentido positivo na reelaboração modernista da psicanálise freudiana. A sexualidade, sensualidade e sua representação, a alegria, o excesso, o pulsional: tudo isso que é herança negra, ameríndia, é assumido como elemento de um povo brasileiro, tornando-se símbolo de brasilidade, retirando a mordaça subjetiva que silenciou o país por anos.

No entanto, devemos ainda assim atentar para o fato de que esses artistas leram Freud e a psicanálise a seu modo. A leitura modernista se apropriou dos conceitos freudianos para a construção de suas hipóteses e ideias sem, todavia, se importar com a aplicação indicada dos termos ou tal como recomendada por Sigmund Freud, o que nos remete à maneira particular de apropriação das ideias freudianas forjada pelos surrealistas franceses e também à incorporação ao próprio gosto empreendida pelos médicos psiquiatras brasileiros.

\footnotetext{
${ }^{8}$ No IEB-USP, podemos conferir sete exemplares da obra de Freud que pertenciam ao autor modernista e compõem o acervo da Biblioteca Mario de Andrade.
} 


\section{CONSIDERAÇÕES FINAIS}

Relembrando a peste freudiana, lançamos mão neste momento da analogia feita entre essa figura simbólica e a difusão do discurso psicanalítico em nosso país. Após análise do cenário de entrada da psicanálise no território nacional, não nos resta dúvida de que a disciplina psicanalítica teria contaminado radical e vigorosamente o discurso nacional.

A peste empreendida por Freud teria, em sua difusão, impactado cultural e socialmenteos espaços em quefoi recebida. Os intérpretes do discurso freudiano, ao se filiarem às teses psicanalíticas, foram se apropriando desse saber, remodelando seus construtos teóricos, estéticos, metodológicos e, ao mesmo tempo, direcionando os caminhos que a doutrina psicanalítica assumiria no Brasil a partir dos discursos que a incorporaram. Dito de outro modo, cada uma dessas vias de incorporação pode se ressignificar a partir do contato com a psicanálise, o que, numa via de mão dupla, acabou dando contornos variados à disciplina que ia se firmando no Brasil. Para além de uma apropriação específica de acordo com a tradição do discurso que se apropriou das ideias freudianas, tratar-se-ia de uma recolocação de todo o contexto cultural, social e literário dos grupos que se apropriaram da psicanálise, inclusive alterando e modulando os próprios rumos das ideias freudianas no país.

Ao nos debruçarmos sobre os pontos de ancoragem da psicanálise no Brasil, deparamo-nos com a particularidade do caso brasileiro: aqui, a difusão da teoria psicanalítica esteve intimamente ligada às demandas da intelligentsia nacional para a construção do projeto de nação e nacionalidade queecoava no país desde o final do século XIX. Nesse cenário de discussão de um projeto nacional, no qual a conformação de um ideal de homem e de povo era a questão central em pauta nos debates, a psicanálise é trazida para o Brasil por setores específicos da psiquiatria e da vanguarda artística. Vai, assim, se desenhando como um novo saber, capaz de oferecer novos procedimentos e meios de abordar a psicologia humana, a formação da personalidade, método de investigação, terapia alternativa, dispositivo rico para investigações estéticas.

Freud e sua teoria atraíram para si grande interesse: as ideias freudianas foram assumindo nuances muito particulares ao longo de sua difusão e institucionalização no país. A caminhada histórica esboçada ao longo do texto retrata a inserção da psicanálise pelas vias do modernismo e do higienismo, que nos leva à reflexão sobre a definição dos rumos que desembocariam nas instituições psicanalíticas no país tal como se apresentam atualmente. Desse modo, é interessante que se configure um esforço contínuo de reflexão sobre os rumos do discurso e da práxis psicanalítica no Brasil desde a chegada da peste freudiana. Se na história de sua contaminação a psicanálise prestou-se às mais variadas apropriações, valendo-se até de dispositivo de adaptação, a contrapartida dessa 
via, qual seja, a sua aproximação de um discurso mais estético, artístico, teria suscitado outros efeitos para a disciplina? Dito de outro modo: se a configuração do discurso psicanalítico pela via da institucionalização e sua proximidade com o higienismo representaram o declínio da participação do modernismo na psicanálise, seria legítimo afirmar que a instituição psicanalítica atual no país seria tributária desta configuração?

Nossa aposta é que este trabalho fecunde novas discussões reflexivas sobre o discurso psicanalítico no Brasil através de seu resgate histórico, o que pode, a nossover, contribuir para a apropriação econstrução efetiva desse campo no país.

Recebido em 14/8/2013. Aprovado em 22/10/2013.

\section{REFERÊNCIAS}

ANDRADE, M. (1978) Aspectos da literatura brasileira. São Paulo: Martins.

. (2001) Macunaíma: o herói sem nenhum caráter. 32 ed. Texto revisto por Telê Porto Ancona Lopez. Belo Horizonte/Rio de Janeiro: Livraria Garnier. (Coleção dos Autores Modernos da Literatura Brasileira)

BICUDO, V. (1948) Contribuição para a história da Sociedade Brasileira de Psicanálise de São Paulo. Arquivos de Neuropsiquiatria, 6, p.69-72.

CANDIDO, A. (2000) Literatura e sociedade. São Paulo: Publifolha.

FACCHINETTI, C. (2001) "Deglutindo Freud, histórias da digestão do discurso psicanalítico no Brasil". (Doutorado), Universidade Federal do Rio de Janeiro, Rio de Janeiro.

. (2003a) Psicanálise modernista no brasil: um recorte histórico.

Physys: Revista Saúde Coletiva, 13(1), p.115-137.

\& PONTE, C. (2003) Da "profissão que não existe" no Brasil. Estados Gerais da Psicanálise. Disponível em: http://egp.dreamhosters.com/ encontros/mundial_rj/download/1_Facchinetti_46110903_port.pdf. Acesso em 10/7/2012.

LOPEZ, T. (1996) Mariodeandradiando. São Paulo: Hucitec.

MAGGIE, Y. (2005) Mário de Andrade ainda vive? O ideário modernista em questão. Revista Brasileira de Ciências Sociais, 20, p.5-25.

MARTINS, L. (1987) A gênese de uma intelligentsia: os intelectuais e a política no Brasil (1920 a 1940). Rev. Bras. de Ciências Sociais 2(4). Disponível em: http://www.anpocs.org.br/portal/publicacoes/rbcs_00_04/ rbcs04_06.htm. Acesso em 8/10/2012.

OLIVEIRA, C. (2002) Os primeiros tempos da psicanálise no Brasil e as teses pansexualistas na educação Ágora, $V(1)$, p.133-154.

(2006) História da psicanálise: São Paulo, 1920-1969. São Paulo: Escuta: Fapesp.

PATTO, M. (1999) Estado, ciência e política na Primeira República: a desqualificação dos pobres. Estudos Avançados, 13, p.167-198. 
PERESTRELLO, M. (1987) História da sociedade brasileira de psicanálise do Rio de Janeiro. Suas origens e fundação. Rio de Janeiro: Imago. (1994) Vanguardas europeias, modernismo brasileiro e psicanálise. Revista Brasileira de Psicanálise, V. XXVIII, p.445-457.

PONTE, C. (1999) "Médicos, psicanalistas e loucos: uma contribuição à história da psicanálise no Brasil". (Dissertação), Escola Nacional de Saúde Pública/Fiocruz, Rio de Janeiro.

PORTO-CARRERO, J. (1927) “O carácter do escolar, segundo a psychanalyse". Tese apresentada na I Conferência Nacional de Educação em Curitiba, p.41-59.

(1929) Ensaios de psicanálise. Rio de Janeiro: Flores e Mano. (1933) Psicanálise de uma civilização. Rio de Janeiro: Guanabara-Koogan.

RIAVIZ, V. (2004) 'Rastros freudianos em Mário de Andrade". (Mestrado), Universidade Federal de Santa Catarina, Florianópolis.

ROCHA, F. (1930) A doutrina de Freud. 2 ed. São Paulo: Cia. Editora Nacional.

ROCHA, G. (1983) Psicanálise e psiquiatria — uma introdução epistemológica ao surgimento da psicanálise no Brasil. (Mestrado), PUC-Rio.

ROUDINESCO, E. \& PLON, M. (Eds.) (1997) Dicionário de Psicanálise. Rio de Janeiro: Jorge Zahar Editor.

(1994) A história da psicanálise na França: a batalha dos cem anos (volume I: 1885/1939) (v.1) Rio de Janeiro: Jorge Zahar.

RUSSO, J. (1997) Dize-me com quem andas... (A doutrina panseuxalista de Freud e a psiquiatria brasileira no início do século) Paper presented at the XXI Encontro Anual da Anpocs, Caxambu. Disponível em: http://www. anpocs.org/portal/index.php?option=com_docman\&task=doc view\&gid=5302\&ltemid=360. Acesso em 15/3/2013.

SAGAWA, R. (1994) História da Sociedade Brasileira de Psicanálise de São Paulo, in NOZEK, L. et al. (Eds.), Álbum de família: imagens, fontes e idéias da psicanálise em São Paulo, p.15-28. São Paulo: Casa do Psicólogo. . (2004) Psicanálise e psicologia no Brasil e em São Paulo: registros históricos, in MASSIMI, M. \& GUEDES, M. d. C. (Eds.) História da psicologia no Brasil: novos estudos. São Paulo: Cortez.

SANTIAGO, S. (2009) Mário, Oswald e Carlos, intérpretes do Brasil. Cadernos de Letras da UFF — Dossiê: Diálogos Interamericanos(38), p.19-34.

SEVCENKO, N. (1992) Orfeu extático na metrópole: São Paulo, sociedade e cultura nos frementes anos 20. São Paulo: Cia. das Letras.

\author{
Luciana Torquato \\ lucianatorquato.psi@gmail.com \\ Guilherme Massara Rocha \\ massaragr@gmail.com
}


